\title{
Use of group treatment among case managers in Department of Veterans Affairs supported housing program
}

\author{
Jack Tsai, PhD; ${ }^{1-2 *}$ Robert A. Rosenheck, MD $^{1-3}$ \\ ${ }^{1}$ Department of Veterans Affairs New England Mental Illness Research, Education, and Clinical Center, West Haven, \\ CT; ${ }^{2}$ Department of Psychiatry, Yale School of Medicine, New Haven, CT; ${ }^{3}$ Department of Epidemiology and Public \\ Health, Yale School of Public Health, New Haven, CT
}

\begin{abstract}
Because the predominant supported housing model includes individual intensive community-based case management, use of group treatments in supported housing has not been adequately studied. This study examined practices and attitudes about groups among case managers in the Department of Housing and Urban Development-Department of Veterans Affairs Supportive Housing (HUD-VASH) program. We examined national administrative HUD-VASH data and an online survey of case managers from eight sites in the New England region, where dissemination of a new group-based model is in progress. Compared with other sites nationally, sites in the New England region had more group contacts, possibly reflecting the dissemination project. Among the New England sites $(n=8)$, administrative data showed that a higher percentage of group contacts was associated with a greater number of clients served and with more contacts per client. Although case manager survey data $(n=55)$ showed generally positive attitudes about using groups, particularly about the potential effectiveness of groups and peer support, greater reported use of groups was not associated with more positive attitudes about groups. These findings suggest providing group treatments in supported housing programs may help case managers stay connected to clients and case managers appear receptive to using groups, though further research is needed.
\end{abstract}

Key words: case management, group treatment, health services, homelessness, HUD-VASH, mental illness, peer support, program evaluation, supported housing, veterans.

\section{INTRODUCTION}

Permanent supported housing programs successfully house homeless adults by providing subsidized housing coupled with intensive community-based case management. The "Housing First" model of supported housing particularly has gained attention both in the United States [1] and abroad [2] as a way to address the needs of homeless clients with severe mental illness. Intensive case management, following the Assertive Community Treatment model, is not, however, likely to be needed by all homeless adults [3-4], many of whom have less serious mental illnesses or primarily have substance use disorders. Intensive case management is also expensive [5] and can be socially isolating and stigmatizing [6]. In fact, one of the most common complaints of adults with severe mental illness living in independent housing is their loneliness and lack of social interaction [7-10].

\footnotetext{
Abbreviations: GIPS = Group-Intensive Peer Support, HUD = Department of Housing and Urban Development, HUD-VASH = HUD-VA Supportive Housing, PHLAG = Peer Housing Location Assistance Groups, VA = Department of Veterans Affairs, VISN $=$ Veterans Integrated Service Network.

*Address all correspondence to Jack Tsai, PhD; 950 Campbell Ave, 151D, West Haven, CT 06516; 203-932-5711, ext 2090. Email: Jack.Tsai@yale.edu

http://dx.doi.org/10.1682/JRRD.2012.04.0073
} 
The Department of Veterans Affairs (VA) healthcare system, one of the nation's largest healthcare systems, has set itself the goal of ending homelessness among veterans and has dramatically increased its funding and resources for homeless services, including expansion of the flagship supported housing program, the Department of Housing and Urban Development (HUD)-VA Supportive Housing (HUD-VASH) [11] program. ${ }^{*}$ As the size of HUD-VASH programs increases, greater critical examination of the specific case management needs of the diverse clients served by HUD-VASH is warranted in terms of both the intensity of community-based services needed and also the potential role of group treatment approaches. Group treatment approaches have been given scant attention, although they may offer important opportunities for peer support and may improve program efficiency. Groups may foster a greater sense of community integration and encourage social integration between members while allowing case managers to meet with several clients at the same time.

Several group-based models of case management for homeless veterans have been developed within VA. One demonstration program called Peer Housing Location Assistance Groups (PHLAG) [12] offered homeless veterans peer support groups led by a case manager to help them find and obtain housing in the open market. The PHLAG program showed success in helping clients obtain independent housing and illustrates one approach to peer support. Another program, the Group-Intensive Peer Support (GIPS) [13] model, provides peer-oriented group treatment as the default mode of case management, with intensive, community-based individual case management provided only when clinically necessary. A recent study of GIPS at one VA site showed that its implementation was associated with greater social integration and faster acquisition of housing vouchers compared with other sites [14]. However, except for the PHLAG and GIPS service models, the extent to which groups are being used in supported housing programs is not well understood.

Aside from the benefits of peer support, the potential of groups to facilitate increased contact with clients in

\footnotetext{
*U.S. Department of Veterans Affairs. Secretary Shinseki details plans to end homelessness for veterans [Internet]. Washington (DC): Department of Veterans Affairs; 2009 Nov 3. Available from: http://www.va.gov/opa/pressrel/pressrelease.cfm?id=1807
}

supported housing programs needs to be examined. Groups allow case managers to provide services to multiple clients simultaneously, which can lead to more efficient care. For example, in psychotherapy, group therapy can be more cost and time effective than individual therapy [15-16]. While case management may be different from psychotherapy, the potential for providing services to groups of clients rather than clients individually may be particularly pertinent to examine as HUD-VASH programs grow and staff seek to deliver more efficient clinical services.

This study examined the current practices and attitudes regarding groups among HUD-VASH programs and case managers in the New England region, where a current project is underway to develop and disseminate the GIPS model. We examined administrative data on the use of groups in HUD-VASH and case manager responses to an online survey. We hypothesized that programs in the New England region would use groups more often because of recent dissemination efforts of the GIPS model. We further hypothesized that programs that used groups would have more contacts with clients and that case managers who reported using groups would also report more positive attitudes about groups.

\section{METHODS}

\section{Program Description}

The HUD-VASH program was implemented as a demonstration project in 1992 at 19 sites serving about 2,000 veterans [17] and in the years since 2007 has expanded to over 132 sites serving over 40,000 veterans, with at least one HUD-VASH program in each state [11]. HUD-VASH offers homeless veterans with disabilities a Section 8 housing voucher funded by HUD and intensive case management from VA clinical staff, who are mostly social workers. A randomized controlled trial of the original HUD-VASH showed that clients in HUD-VASH had more days housed than those who only received case management without subsidized housing or those who only received standard care [18]. However, there were no group differences on mental health and quality of life outcomes, although HUD-VASH clients showed greater improvement in alcohol and drug problems [19].

The GIPS model was developed in 2009 at the VA Connecticut Healthcare System [13] and is in the process of being disseminated to other VA facilities in the New 
England Veterans Integrated Service Network (VISN) 1. The fundamental shift in the model is that instead of individual, intensive community-based case management services being the default mode of support, clients are expected to attend group meetings for their primary support. Clients are still assigned individual case managers, but case managers lead group meetings to provide clinical services and facilitate peer education. Individual case management is provided on an as-needed basis rather than being a required part of the program.

Dissemination of the GIPS model, thus far, has been through lectures and conference calls presenting the model didactically and through direct coaching at some sites in the use of the model. Because VA sites are organized by VISNs, the GIPS model has also been promoted by VISN 1 leadership. However, it is difficult to assess exactly which sites have been influenced by GIPS dissemination (many sites may have been influenced indirectly through VISN 1eadership or through informal communication with other VAs). As a result, the present study does not focus on examining individual sites in VISN 1, but on the sites as a group representing the early phases of the GIPS dissemination process in VISN 1.

\section{Data Source}

Administrative clinical stop code data were used, which are aggregated data of clinical encounters with specific codes to describe the type of procedures or services offered during the encounter. Data from October 1, 2010, to December 31, 2011, were obtained on the number of clients, total number of group contacts, and total number of individual client contacts among HUD-VASH programs nationally and specifically from eight sites in VISN 1, which included facilities at Togus, Maine; Manchester, New Hampshire; White River Junction, Vermont; Providence, Rhode Island; West Haven and Newington,
Connecticut; Boston, Massachusetts; Northampton, Massachusetts; and Bedford, Massachusetts.

An online anonymous survey of HUD-VASH case managers in VISN 1 was conducted using SurveyMonkey (Palo Alto, California). The survey consisted of 10 questions: 5 questions asked case managers to rate the extent to which they are currently using certain practices and groups in their HUD-VASH programs, and the remaining 5 asked case managers to rate their agreement toward statements about the potential role of groups in HUD-VASH. Items were rated on a 5-point scale from 1 (not at all/strongly disagree) to 5 (to a great extent/strongly agree). The mean response to the first 5 questions was calculated for a group use score (Cronbach $\alpha=0.63$ ), and the mean response to the last 5 questions was calculated for a group attitudes score (Cronbach $\alpha=0.60$ ). Items that were worded negatively were reverse-coded. The questionnaire is available from the first author on request. Use of the survey was approved by the institutional review boards of the VA Connecticut Healthcare System and Yale School of Medicine.

\section{RESULTS}

As shown in Table 1, HUD-VASH administrative data indicate that VA Connecticut, which first developed and implemented the GIPS model, had 29.38 percent greater group contacts and 2.17 more contacts per client than other sites in VISN 1. Six out of the eight sites in VISN 1 (including VA Connecticut) provided some group contacts, and the top four sites with the largest number of clients also had the most group contacts. Compared with other sites nationally, sites in VISN 1 had an 18.15 percent greater percentage of group contacts and 0.83 more contacts per client, which was statistically significant $(t=2.49, p=0.04)$.

Table 1.

Number of clients and contacts in Department of Housing and Urban Development-Department of Veterans Affairs (VA) Supportive Housing programs in Veterans Integrated Service Network (VISN) 1 and nationally.

\begin{tabular}{lccr}
\hline \multicolumn{1}{c}{ Contact Type } & $\begin{array}{c}\text { VA Connecticut } \\
(\boldsymbol{n}=\mathbf{3 2 8} \text { clients) }\end{array}$ & $\begin{array}{r}\text { Other VISN 1 Sites* }^{*} \\
(\boldsymbol{n}=\mathbf{1 , 7 9 6} \text { clients) }\end{array}$ & $\begin{array}{r}\text { All Other Sites Nationally } \\
(\boldsymbol{n}=\mathbf{4 1 , 3 1 7} \text { clients) }\end{array}$ \\
\hline Group Contacts $(n)$ & 995 & 1,384 & 10,212 \\
Individual Face-to-Face Contacts $(n)$ & 1,084 & 6,106 & 141,956 \\
Total Contacts $(n)$ & 2,079 & 7,490 & 152,168 \\
\% of Total Contacts that Were Group Contacts & 47.86 & 18.48 & 6.71 \\
Total Contacts per Client $(n)$ & 6.34 & 4.17 & 3.68 \\
\hline
\end{tabular}

* Other New England VISN 1 sites excluding VA Connecticut.

${ }^{\dagger}$ Excluding VISN 1 sites. 
Among all sites in VISN 1, nonparametric correlations of administrative data at the site level $(n=8)$ using Spearman rho $(\rho)$ showed that the number of clients served was significantly associated with the percentage of group contacts ( $\rho=0.86, p=0.002)$. The percentage of group contacts and the number of contacts per client were not significantly associated, although the effect size was large $(\rho=0.69, p=0.06)$.

Table 2 displays results of the survey of case managers at VA Connecticut and other sites in VISN 1 on their use of and attitudes toward groups in HUD-VASH. Of the 75 case managers across 8 sites, 55 responded (73.33 percent response rate). Consistent with HUD-VASH administrative data, HUD-VASH case managers at VA Connecticut had a significantly higher group use score than other sites in VISN 1, as well as higher scores on several individual items related to group use reflecting implementation of the GIPS model.

However, there were no significant differences between VA Connecticut and other sites in VISN 1 on the group attitudes score or on individual items related to attitudes about groups. Across the eight sites in VISN 1, case managers rated all five items related to group attitudes positively (above 3, "neither agree nor disagree"), except one item in which most sites agreed that "not all clients would be appropriate for groups.” The two items case managers rated the highest across all sites in VISN 1 were that "groups can be clinically effective" and that "clients can benefit from peer support in groups."

At the case manager level $(n=55)$, a significant association was found between the number of clients seen weekly and the mean group use score $(\rho=0.35, p=$ 0.01). However, the association between clients seen weekly and the mean group attitudes score was not significant ( $\rho=0.16, p=0.26$ ). The group use scores and the group attitudes score were borderline significantly correlated $(\rho=0.27, p=0.05)$.

\section{DISCUSSION}

This study showed that most HUD-VASH programs in the Northeast region of the United States used groups as part of their case management services, which may reflect recent dissemination efforts of the GIPS model. We found no prior studies that examined the use of groups in HUD-VASH or any other supported housing

Table 2.

Survey results (mean \pm standard deviation) of Department of Housing and Urban Development-Department of Veterans Affairs (VA) Supportive Housing (HUD-VASH) case managers in Veterans Integrated Service Network (VISN) 1.

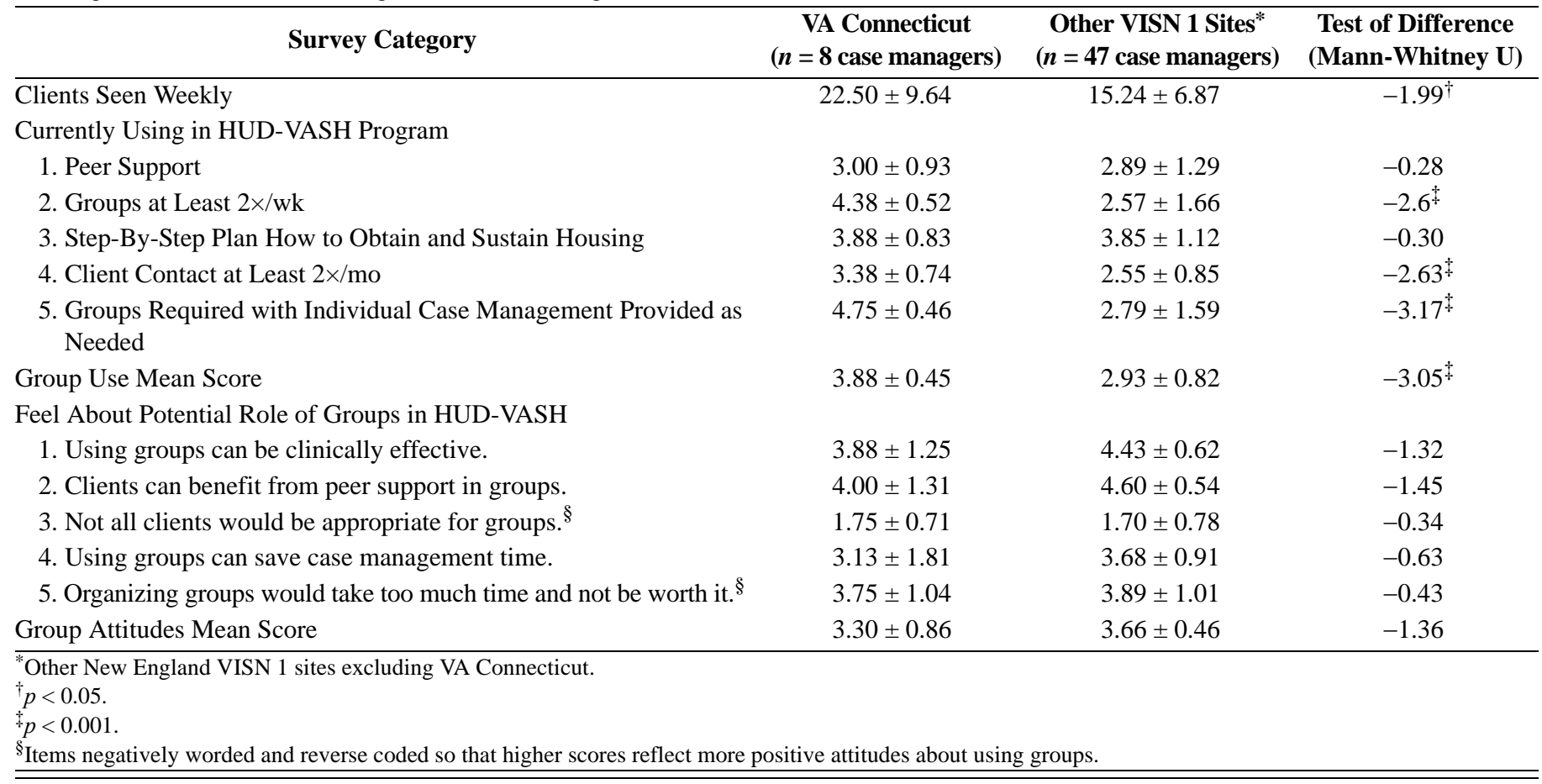


program. The results of this study illustrate potential dissemination effects of the new GIPS model, and they also showed that there are other HUD-VASH sites in the country offering groups for their clients. Further research is needed on why other sites have chosen to offer groups, what purpose they serve, and whether groups used in supported housing programs are clinically effective.

HUD-VASH sites that used groups more often saw more clients and had more contacts per client, suggesting a potential for greater efficiency. This finding was consistent with the study hypothesis and may reflect practical efforts to provide case management services and stay connected to clients while carrying large caseloads. Use of groups to maintain contact with clients may allow greater flexibility in providing intensive individual case management to clients who need it.

Although sites that used groups more often had more contacts with their clients, they did not necessarily report more positive attitudes about using groups, although the general level of attitudes about groups was positive. The number of groups offered was not associated with more positive attitudes about groups; however, this may be because case managers at all sites generally reported positive attitudes about using groups in HUD-VASH. Notably, case managers reported the most positive attitudes about groups being clinical effective and clients benefitting from peer support in groups, suggesting that HUD-VASH case managers are willing to incorporate groups into their case management services.

Taken together, these findings suggest using groups in supported housing programs like HUD-VASH may help case managers maintain more intensive contact with their clients. However, several study limitations are worth mentioning. Sites that had more group contacts may have differed from other sites in unmeasured ways (e.g., leadership, team cohesiveness, diversity). No data on client outcomes were collected, and it is possible that pressures for efficiency and efforts to adopt less individual-intensive models of care may undermine client outcomes. Alternatively, groups may offer clients opportunities for therapeutic peer support, social interaction, and community integration not available in individual case management.

The extent to which the GIPS model was disseminated and the specific sites that were influenced by the dissemination were not measured. The small sample size precluded in-depth statistical analyses at the site-level to tease out the effects of dissemination. Moreover, the internal consistency (alpha coefficients) of survey mea- sures was somewhat low, which may have affected correlational analyses. There was a fairly high response rate to surveys, but not all case managers completed the survey, which may limit the generalizability of the findings.

Importantly, the findings of this study show that a gap in the research literature exists on the use of groups in the provision of supported housing services. Although this study found that some HUD-VASH sites are using groups, this preliminary study may be the first describing the general use and attitudes of groups in supported housing programs. A larger, more detailed survey related to use of groups in HUD-VASH sites nationally and in other supported housing programs would be informative. More research is also needed to examine how groups should be used and integrated into supported housing services and their effect on client outcomes and program costs. Groupbased models like GIPS [13] deserve further attention because they may offer services that promote greater peer support and social integration while increasing the efficiency of staff.

\section{CONCLUSIONS}

Dissemination of a group-based model of case management has been well-received by several HUD-VASH programs and may provide a method of maintaining frequent contact with clients in large programs. However, groups are not commonly used in HUD-VASH programs nationally according to administrative data, and further research is needed on when groups are particularly indicated.

\section{ACKNOWLEDGMENTS}

Author Contributions: Drs. Tsai and Rosenheck conceptualized this study, collected data, conducted analyses, and wrote the manuscript together.

Financial Disclosures: The authors have declared that no competing interests exist.

Funding/Support: This material was based on work supported by a career development award (CDA-2) from the VA Health Services Research and Development Service.

Institutional Review: Use of the survey was approved by the institutional review boards of the VA Connecticut Healthcare System and Yale School of Medicine.

Participant Follow-Up: The authors have no plans to notify the study subjects of the publication of this article because of a lack of contact information. 


\section{REFERENCES}

1. Tsemberis S, Gulcur L, Nakae M. Housing First, consumer choice, and harm reduction for homeless individuals with a dual diagnosis. Am J Public Health. 2004;94(4):651-56. [PMID:15054020]

http://dx.doi.org/10.2105/AJPH.94.4.651

2. Pleace $\mathrm{N}$. The ambiguities, limits and risks of Housing First from a European perspective. Eur J Homelessness. 2011;5(2):113-27.

3. Kasprow WJ, Rosenheck RA. Outcomes of critical time intervention case management of homeless veterans after psychiatric hospitalization. Psychiatr Serv. 2007;58(7):929-35. [PMID:17602008] http://dx.doi.org/10.1176/appi.ps.58.7.929

4. Susser E, Valencia E, Conover S, Felix A, Tsai WY, Wyatt RJ. Preventing recurrent homelessness among mentally ill men: a "critical time" intervention after discharge from a shelter. Am J Public Health. 1997;87(2):256-62. [PMID:9103106] http://dx.doi.org/10.2105/AJPH.87.2.256

5. Latimer EA. Economic impacts of assertive community treatment: a review of the literature. Can J Psychiatry. 1999;44(5):443-54. [PMID:10389605]

6. Strickler DC. Requiring case management meetings to be conducted outside the clinic. Psychiatr Serv. 2011;62(10): 1215-17. [PMID:21969649] http://dx.doi.org/10.1176/appi.ps.62.10.1215

7. Tsai J, Bond GR, Salyers MP, Godfrey JL, Davis KE. Housing preferences and choices among adults with mental illness and substance use disorders: a qualitative study. Community Ment Health J. 2010;46(4):381-88. [PMID:19898935] http://dx.doi.org/10.1007/s10597-009-9268-6

8. Friedrich RM, Hollingsworth B, Hradek E, Friedrich HB, Culp KR. Family and client perspectives on alternative residential settings for persons with severe mental illness. Psychiatr Serv. 1999;50(4):509-14. [PMID:10211732]

9. Nelson G, Hall GB, Squire D, Walsh-Bowers RT. Social network transactions of psychiatric patients. Soc Sci Med. 1992;34(4):433-45. [PMID:1566125] http://dx.doi.org/10.1016/0277-9536(92)90304-9

10. Siegel CE, Samuels J, Tang DI, Berg I, Jones K, Hopper K. Tenant outcomes in supported housing and community residences in New York City. Psychiatr Serv. 2006;57(7):982-91. [PMID:16816283]

http://dx.doi.org/10.1176/appi.ps.57.7.982

11. U.S. Department of Veterans Affairs. HUD-VASH eligibility criteria. Washington (DC): Department of Veterans Affairs; 2012 [cited 2012 April 8]. Available from: http://www.va.gov/homeless/hud-vash.asp

12. Lucksted A, Sturm V, Lincoln SH, Bellack A. Peer housing location assistance groups VACO/OMHS feasibility pilot project. Baltimore (MD): VISN-5 Mental Illness, Research Education and Clinical Center; 2008.

13. Tsai J, Rosenheck RA, Sullivan J, Harkness L. A groupintensive peer support model of case management for supported housing. Psychol Serv. 2011;8(3):251-59. http://dx.doi.org/10.1037/a0024837

14. Tsai J, Rosenheck RA. Outcomes of a group intensive peersupport model of case management for supported housing. Psychiatr Serv. 2012;63(12):1186-94. [PMID:22983658] http://dx.doi.org/10.1176/appi.ps.201200100

15. Tucker M, Oei TP. Is group more cost effective than individual cognitive behaviour therapy? The evidence is not solid yet. Behav Cogn Psychother. 2007;35(1):77-91. http://dx.doi.org/10.1017/S1352465806003134

16. Morrison N. Group cognitive therapy: Treatment of choice or sub-optimal option? Behav Cogn Psychother. 2001;29(3): 311-32. http://dx.doi.org/10.1017/S1352465801003058

17. Kasprow WJ, Rosenheck RA, Dilella D, Carter R, Cavallaro L. Health care for homeless veterans programs: fourteenth annual report. West Haven (CT): Northeast Program Evaluation Center; 2001.

18. Rosenheck RA, Kasprow W, Frisman L, Liu-Mares W. Cost-effectiveness of supported housing for homeless persons with mental illness. Arch Gen Psychiatry. 2003;60(9): 940-51. [PMID:12963676] http://dx.doi.org/10.1001/archpsyc.60.9.940

19. Cheng AL, Lin H, Kasprow WJ, Rosenheck RA. Impact of supported housing on clinical outcomes: analysis of a randomized trial using multiple imputation technique. J Nerv Ment Dis. 2007;195(1):83-88. [PMID:17220745] http://dx.doi.org/10.1097/01.nmd.0000252313.49043.f2

Submitted for publication April 25, 2012. Accepted in revised form September 11, 2012.

This article and any supplementary material should be cited as follows:

Tsai J, Rosenheck RA. Use of group treatment among case managers in Department of Veterans Affairs supported housing program. J Rehabil Res Dev. 2013;50(4): 471-76. http://dx.doi.org/10.1682/JRRD/2012.04.0073

ResearcherID/ORCID: Jack Tsai, PhD: D-3889-2013

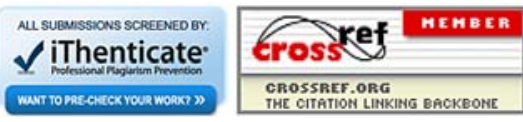

